\title{
PEMANFAATAN MICROSOFT WORD DALAM \\ PEMBUATAN KARYA ILMIAH BAGI GURU \\ DI MTS. AL-FURQON BANJARMASIN
}

\author{
Muthia Farida, Dian Agustini, dan Muhammad Rais Wathani \\ Fakultas Teknologi Informasi, Universitas Islam Kalimantan MAB \\ Email : muthiafarida59@yahoo.co.id
}

\begin{abstract}
Improving the quality of teachers can be seen from the productivity of teachers in making scientific papers, either in the form of articles, books, learning materials, modules and so on. The lack of ability of teachers in the mastery of the software that is devoted to the creation of the scientific works, making the trend of teachers utilizing software already used, i.e. microsoft office especially is Microsoft Word, but the use of this software is not yet utilizing features existing in it optimally utilizes features, such as the creation of a table of contents automatically, automatic bibliography creation, creation of a list of table/list of pictures automatically automatic index creation, Glosarry, Citation, and so on. Many teachers are still using manual way to make it, but if the diitinjau usage of the time, of course this requires a lot more time allocation primarily requires a very high precision.

The teachers only know MS Word with basic features as the software for typing, andmakes writing a simple, and yet know advanced features in MS Word that should beused to ease the writing of scientific papers as described earlier.
\end{abstract}

Keywords:Microsoft Office, Mts Al-Furqon, Scientific Papers, Software, Teacher

\section{PENDAHULUAN}

Peningkatan kualitas guru dapat dilihat dari produktifitas guru dalam membuat karya ilmiah, baik berupa artikel, buku, modul, bahan ajar dan sebagainya. Minimnya kemampuan guru dalam penguasaan perangkat lunak yang dikhususkan untuk pembuatan karya ilmiah tersebut, membuat kecenderungan guru memanfaatkan perangkat lunak yang sudah biasa digunakan, yaitu microsoft office terutama adalah Microsoft Word, namun penggunaan perangkat lunak inipun belum memanfaatkan fitur-fitur yang ada di dalamnya secara optimal, seperti memanfaatkan fitur pembuatan daftar isi otomatis, pembuatan daftar pustaka otomatis, pembuatan daftar tabel/daftar gambar otomatis, pembuatan indeks otomatis, Glosarry, Citation dan sebagainya. Banyak guru yang masih menggunakan cara manual untuk membuatnya, padahal jika diitinjau dari pemakaian waktu, tentunya hal ini membutuhkan lebih 
banyak alokasi waktu terutama memerlukan ketelitian yang sangat tinggi.

\section{KHALAYAK SASARAN}

Kegiatan pelatihan komputer ini khalayak sasarannya adalah kegiatan yang diikuti oleh para guru-guru di Mts Al-Furqon Banjarmasin. Dengan tujuan agar para guru dapat membuat/menyusun karya ilmiah baik berupa artikel maupun bahan ajar (modul/buku teks/presentasi) dengan lebih mudah dan rapi.

\section{METODE}

Untuk mencapai tujuan yang diharapkan, maka pelaksanaan pelatihan komputer ini menggunakan 3 metode, yaitu : Tutorial $\rightarrow$ Instruktur menjelaskan tentang Microsoft Office Word dengan menggunakan alat bantu LCD, sehingga peserta dapat memahami tanpa harus mendengarkan teori atau membaca diktat terlebih dulu. Praktek Mandiri $\rightarrow$ Setiap peserta melakukan praktek berupa proses menjalankan komputer, membuka lembar word, fitur-fitur, toolbar dan lain sebagainya.Tanya Jawab $\rightarrow$ Peserta dapat langsung bertanya kepada Tim Pengabdian pada masyarakat yang mendampingi mereka selama kegiatan berlangsung.

\section{HASIL DAN PEMBAHASAN}

Pelaksanaan program pelatihan MS. Word dalam membuat karya ilmiah bagi para guru di Mts. Al-Furqon dilakukan dengan pelatihan individual secara langsung dan memberikan materi berupa handout kepada para peserta. Diharapkan para guru dapat memanfaatkan fitur-fitur yang tersedia di dalam MS. Word secara optimal serta dapat menyusun karya ilmiah baik berupa artikel ataupun bahan ajar dengan efesien dan rapi.

\section{FOTO KEGIATAN}
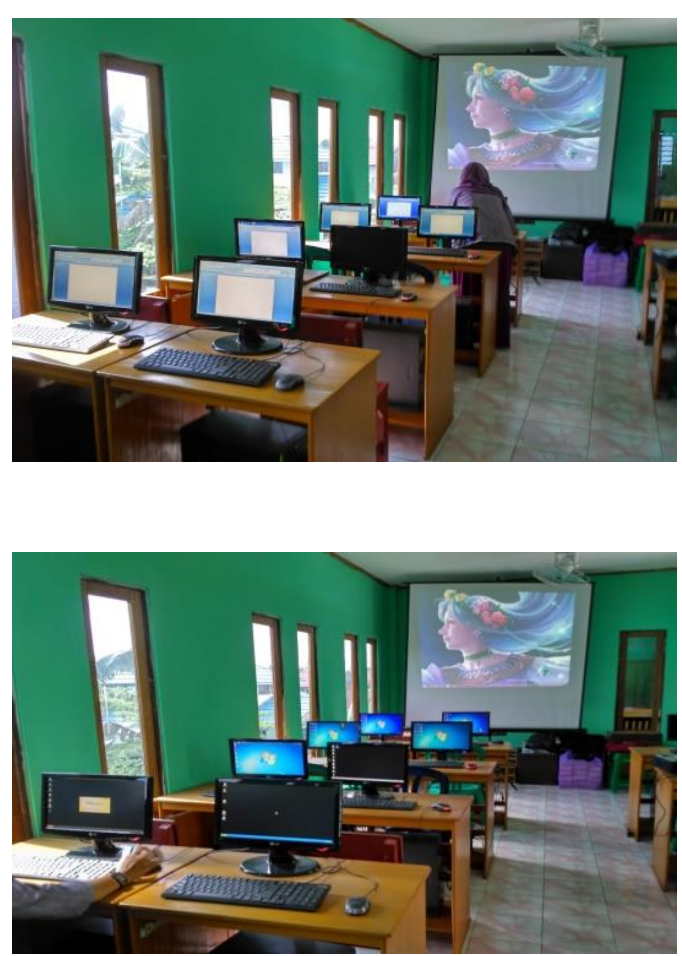


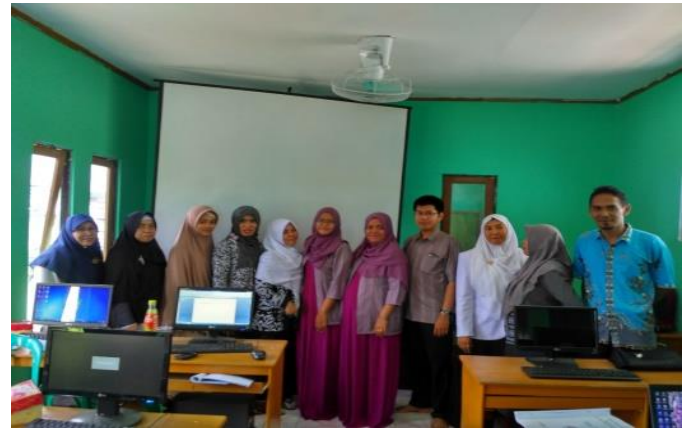

\section{KESIMPULAN}

Dari hasil pelaksanaan kegiatan Pemanfaatan Microsoft Word dalam Pembuatan Karya Ilmiah bagi guru di MTs. Al-Furqon Banjarmasin didapatkan kesimpulan bahwa kegiatan pembelajaran ini sangat bermanfaat bagi para guru untuk menunjang kegiatan belajar mengajar kepada siswa. Dan diharapkan agar bisa diterapkan semua guru yang mengikuti kegiatan pelatihan tersebut.

\section{DAFTAR PUSTAKA}

A, K. (2015). Word 2013 Panduan Karya Tulis Ilmiah. Elex Media Komputindo.

Jarot S., S. A. (2012). Buku Pintar Microsoft Office 2007 \& 2010 Word Excel-Power Point. Media Kita.

Madcoms. (2013). Microsoft Word 2013. Penerbit Andi. 